\title{
UM CORPO QUE NÃO CAI: A CIDADE E O SUJEITO MIGRANTE EM SUSPENSÃO
}

\author{
Liane Schneider \\ Universidade Federal da Paraíba \\ João Pessoa, PB, BR
}

\section{Resumo}

Neste artigo propomos a discussão de diversas teorias culturais contemporâneas sobre o corpo, o sujeito migrante e sua relação com as fronteiras, discurso aqui justaposto à crítica literária, enfocando uma narrativa em que a protagonista e as representações de seu corpo desvelam marcas linguísticas e culturais em um espaço de inserção provisória. Buscamos verificar se o estado de suspensão é, na narrativa em questão, uma estratégia de sobrevivência psicológica, linguística e cultural encontrada pela protagonista ao longo de seus deslocamentos. O romance em foco é o de Paloma Vidal, intitulado Algum lugar (2009), a partir do qual tecemos nossas considerações sobre corpo migrante e estado de suspensão, conceito que tangencialmente se aproxima da ideia de entre lugar, mas numa perspectiva mais espacial do que geográfica. Utilizamos as teorias desenvolvidas por Elizabeth Grosz, Glória Anzaldúa, Susan Bordo, entre outras, na leitura crítica aqui apresentada do romance em foco.

Palavras-chave: migrante; corpo; suspensão; fronteira.

\section{A BODY THAT DOES NOT FALL DOWN: THE CITY AND THE MIGRANT SUBJECT IN SUSPENSION}

\begin{abstract}
In this article we propose the discussion of different cultural theories of today on the body, the migrant subject and its relation to the concept of frontier, always in dialogue with literary criticism. We focus on a narrative in which the protagonist as well as the representation of her body unveil cultural and linguistic markers, always in a space of provisional insertion, planning to verify if the state of suspension is a survival strategy in pshycological, linguistic and cultural ways. The narrative we deal with is Algum lugar (2009), by Paloma Vidal, a novel from which we weave our considerations on the migrant body and its state of suspension, a concept we see as in dialogue with the concept of in-between, but here in a perspective arranged in ways that are more spacial than geographic. We take as our theoretical foundations Elizabeth Grosz, Glória Anzaldua, Susan Bordo, among others for developing the critical reading we present on the selected novel.
\end{abstract}

Keywords: migrant; body; suspension; frontier.

\section{Introduzindo e localizando a discussão}

Em Algum lugar (2009), romance de Paloma Vidal, somos apresentadas a um mundo ficcional que se movimenta especialmente por entre dois lugares - Los Angeles e Rio de Janeiro. Os dois países envolvidos, os Estados Unidos e o Brasil, aparecem apenas como pano de fundo, sugerindo que as cidades, nesse caso, seriam bem mais fundamentais do que as nações no campo das referências de indivíduos inseridos nas teias da globalização contemporânea. Essas duas cidades, L.A. e Rio, invariavelmente mencionadas pelo olhar e voz da protagonista, apresentam-se como que flutuando lado a lado, mantendo relação com os objetivos que a personagem redefine a cada momento, planos de vida que tomam lugar cá e lá, que acabam também boicotados 
nos dois locais. A voz que nos fala ao longo do romance é inaugurada/parida em Buenos Aires, cresce e avoluma-se no Rio, tentando posteriormente fixar-se em Los Angeles, sem previsões de quão longa essa permanência será. Não sabemos se o casal que nos é apresentado pretende, de fato, migrar para Los Angeles/EUA ou se apenas os anos de formação educacional conseguirão mantê-los por ali, longe de seus lugares anteriores de pertencimento. Como que impulsionada pela presença e influência marcante da(s) cidade(s), a narrativa de Vidal nos faz olhar para esses corpos humanos construídos de forma a melhor compreender o não lugar, ou o "algum lugar", sugerido no título da publicação.

\section{Deslocamentos e fronteiras: corpos suspensos}

Glória Anzaldúa (1987, p. 3) já defendia em seu livro Borderlands que a fronteira assume o papel de distinguir o grupo formado por nós, de um outro, formado por eles, apontando que o terreno ocupado por essa delimitação geográfica seria, no campo das imagens, como uma faixa minúscula de divisão alinhavada sobre uma montanha muito íngreme. Já são aí insinuados a instabilidade e os riscos implicados na ocupação de tais zonas instáveis em relação a ambos os lados, indicando a compreensão da fronteira como limítrofe, tanto em termos geográficos como espaciais, o que especialmente nos interessa. Nessa mesma linha de raciocínio, compreendemos de imediato o porquê de se conectar frequentemente o conceito de fronteira a algo tênue, vago, em estado de constante transição e mudança, concepção defendida por autoras como Moraga e Anzaldúa (1983), Klahn (2003), Sandowski-Smith (2008), entre outras.

Estudos na área de literatura que justapõem diferentes historiografias literárias e culturais, como os que se voltam às literaturas chicanas, ou sobre várias outras que se hifenizaram após a migração, como as asiático -americanas, as afro-americanas, entre outras, enfocam um texto que se produz exatamente a partir da noção inevitável de fronteira, em seu sentido amplo, ou seja, de fronteira geográfica, cultural, linguística, social, étnica. Essas vozes, que frequentemente escrevem a partir do lugar onde ocorreu a recente instalação dos sujeitos, consequência de migrações reais ou imaginadas, de- monstram interesse nos processos decorrentes dos deslocamentos vivenciados por esses. Avtar Brah (1996, p. 178) aponta, ao tentar pensar quem seriam, enfim, os/ as migrantes contemporâneos: "as pessoas em deslocamento podem tanto ser trabalhadores migrantes (com ou sem documentos), especialistas altamente qualificados, empresários, estudantes, refugiados e pessoas em busca de asilo político, ou mesmo membros familiares de um grupo anterior de migrantes".

No caso da narrativa de Vidal, que aqui enfocamos e através da qual problematizamos a temática do corpo migrante, a pessoa em deslocamento é uma mulher que faz parte de um grupo marcado como elite intelectual no Brasil - alguém que saiu do país com o objetivo de cursar o doutorado nos Estados Unidos, o que não seria algo facilmente concretizado pela maior parte da população brasileira. O corpo dessa personagem-mulher realmente acaba se tornando o que Sandra Regina G. Almeida (2013, p. 94) denomina de "elemento simbólico e material no qual fatores sociais e históricos são inscritos", em sintonia com o que também defende Susan Bordo (1993), o que será destacado na análise do romance. Acreditamos que as lutas feministas que se tornaram referência ao longo dos tempos, como também as discussões teóricas sobre o corpo da mulher, dando espaço a temas e lemas tão defendidos ao longo das últimas décadas, que explicitam frases do tipo "meu corpo me pertence", implicam a compreensão de que qualquer autonomia, bem como dificuldade vivenciada no campo social, é diretamente experimentada através do corpo, no caso, um corpo com marcas de gênero, além das étnico-raciais - no romance em tela, um corpo de mulher.

Um chamamento que tem sido citado (e pichado) em diversos contextos nos dias de hoje, marcando presença em intervenções organizadas pelos movimentos feministas, afirma: "A(r)me-se contra o machismo", sugerindo que, no caso, tanto o ato de 'amar' (a si mesma) quanto o de 'armar-se' estão diretamente aqui vinculados à defesa do corpo no que diz respeito a lógicas e práticas que oprimem, restringem, diferenciam negativamente indivíduos de acordo com suas identificações biológicas. Há nessas construções discursivas uma ideia de que o corpo (e aqui, a mulher que o possui) se de- 
fende através das armas político-teóricas no campo da razão, e através de uma auto aceitação e valorização de si, enfim, de um amor próprio que pode assegurar a sobrevivência e o florescimento pessoal no campo dos afetos e das relações públicas e privadas, ainda que em terreno pouco propício.

Enquanto Adrienne Rich (2002, p. 20) dá destaque à "política da localização" no que diz respeito ao corpo da mulher, considerando essa (via seu corpo) a perfeita geografia para a inserção mais satisfatória das mulheres nas relações que se estabelecem socialmente entre centro e periferia, consideramos que algo bastante diferente ocorre no texto que compõe nosso corpus literário quanto a essa lógica. Obviamente a geografia atrelada ao corpo sempre tem marcas outras que sua materialidade - não é possível limitar o corpo a um lugar de existência, nem a uma forma única de ocupação de espaço. O corpo de nossa protagonista, por exemplo, indica a extensão de seu esvaziamento, de sua falta de referências em quaisquer das geografias pelas quais circulam, no caso, Los Angeles e Rio de Janeiro centralmente, e Buenos Aires, de forma intensa, embora mais tangencial. $\mathrm{O}$ fato de ocorrer uma migração não parece ser a razão para tanta falta de sintonia no que se refere à localização, já que essa sensação é problematizada em todo o processo de deslocamento, o que bem anuncia a epígrafe de Silvina Ocampo, escolhida por Vidal: "se llega a um lugar sin haber partido de otro, sin llegar". Outro ponto crucial na narrativa é que o casal - a protagonista e seu companheiro (M.) - chega a Los Angeles já em voos separados, quase se perdendo num "aeroporto que faz questão de expulsá-los" (VIDAL, 2009, p.16), não havendo conforto qualquer nas salas de espera que são ali disponibilizadas ao público. Como conclui a protagonista: "Não consigo acreditar que já estamos perdidos sem sequer sair do aeroporto", em seguida admitindo que "a decisão" de virem em vôos separados logo "parecerá um primeiro passo em falso" (idem).

Conforme a teórica Assumpta Camps, em artigo onde discute o "estar no meio do caminho" vivenciado por sujeitos em trânsito (ou na fronteira), temos o que segue:

A fronteira é um lugar privilegiado para se considerar os fenômenos de transmissão cultural e a nossa relação com o Outro. Seria algo como uma redefinição de nós mesmas através do olhar do Outro. Dito de outra forma, esse seria o observatório preferencial para ver o centro cultural a partir da periferia e a periferia cultural a partir do centro. (CAMPS, 2011, p. 341)

Acrescente-se o que aponta o Dicionario de estudios culturales latino-americanos, ao perceber as fronteiras como capazes de exercer diferentes papeis em diferentes momentos e contextos:

As fronteiras separam, unem, delimitam, marcam a diferença e a similitude, mas também produzem espaços intersticiais, novos espaços que inauguram relações. Essas podem ser burladas, acatadas, cruzadas, transgredidas, imaginadas, reais, reinventadas e destruídas. Elas confinam e libertam. Protegem e torturam. (SMURKMUK; IRWIN, 2009, p. 106)

Como veremos a seguir, em Algum lugar as fronteiras dizem muito mais respeito a um corpo em isolamento quase que absoluto e que flutua em altura e nível próprios, o que ocorre por várias frentes - étnicas, linguísticas, psicológicas. Contudo, é exatamente a partir dessa localização na fronteira que a protagonista se vê obrigada a revisitar etapas de sua vida, buscando alguma compreensão sobre os rumos que essa seguiu.

\section{Algum lugar ou lugar nenhum: o corpo/texto em suspensão e a cidade}

Em texto de Elizabeth Grosz (2011), intitulado "Corpos-cidades", a autora examina atentamente de que forma a relação entre uma entidade física - o corpo humano - e um arranjo social externo - a cidade em suas variadas formatações - vem sofrendo modificações em tempos contemporâneos. Logo no início de seu texto, Grosz (2011, p.89) afirma que não quer repetir os velhos binarismos ao definir o que entende por corpo; na verdade, a autora busca "desafiar e (...) ultrapassar as oposições que têm determinado a vulgar compreensão" desse termo e as noções a ele atreladas. Já Bordo (1997, p. 20) defende que "nossos corpos são treinados, moldados e marcados pelo cunho das formas históricas 
predominantes de individualidade, desejo, masculinidade e feminidade". Portanto, considerando o que defendem Grosz e Bordo, podemos afirmar que o corpo da protagonista em Algum lugar está vivenciando uma tentativa outra de "treinamento social", afinado com uma história cultural diferenciada nesse novo local que passa a ocupar ao fixar-se em Los Angeles.

Grosz "despe a corporalidade do corpo" em busca de examinar este em suas relações, principalmente as que se estabelecem no espaço urbano. Por outro lado, aponta que "a cidade é a condição e o meio no qual a corporalidade se produz social, sexual, e discursivamente" (GROSZ, 2011, p. 91). Percebemos, pelas palavras da autora, que, por seu ponto de vista, a cidade propicia a construção e a desconstrução do corpo - sua materialização, visibilidade e seu perfil relacional que escapa o estado de ser simples matéria. Por outro lado, Sandra R. G. Almeida (2015, p. 30) destaca, ao comentar a produção literária brasileira contemporânea, que "o paradigma da mobilidade e do trânsito em espaços urbanos têm sido marca recorrente de narrativas de autoria feminina, em especial aquelas publicadas a partir de 2001". Portanto, observar as construções literárias que se voltam a essa retomada do urbano, do citadino, especialmente com enfoque em mulheres e seus corpos, nos parece uma discussão apropriada para tratar da temática que propomos discutir. Especificamente no caso da narrativa de Vidal, a corporalidade (bem como a possibilidade de sua produção) tem se mostrado largamente emudecida.

Nossa protagonista se diz "em estado de nomadismo" durante as primeiras semanas em que tenta se inserir em Los Angeles com seu companheiro M. Os dois circulam de forma "desorientada" pela cidade, buscando um lugar para morar ao longo dos anos em que o estudo (seu curso de doutorado) deverá assumir papel central na vida do casal (VIDAL, p.18-19). Percebem, depois de algum tempo, que não estão preparados para lidar com uma cidade não mais pensada para o humano/pedestre, e sim, para a máquina/carro:

Só alguns meses depois, andando de carona com algum amigo, começaremos a entender que em Los Angeles as avenidas não são exa- tamente vias de transporte; para se locomover, existem as freeways, que conformam um mapa sobreposto à cidade, um mapa próprio, com suas entradas e saídas que guardam uma relação apenas tangencial com o desenho quadriculado, remanescente de uma cidade em que a calçada ainda fazia algum sentido. (VIDAL, p. 19)

Portanto, a protagonista, que está desenvolvendo pesquisa de pós-graduação, atividade intelectual geralmente marcada como apartada do mundo prático de outras profissões que seguem as regras de mercado, encontra-se em um novo território, local onde as línguas que (parcialmente) domina - o espanhol, herança quase genética pelo lado materno da família - e o português, apropriado ao longo dos anos vividos no Brasil, pouco ajudam em sua integração na nova cidade. Além disso, o hábito de conhecer lugares através de passeios, tão comuns e importantes para uma infinidade de escritores e escritoras, pensadores, enfim, ao longo da história cultural ocidental, torna-se praticamente impossível, como lemos:

As longas idas e vindas da universidade tornaram-se uma silenciosa tortura. Somos massacrados diariamente pela cidade, que nos faz pagar nosso desconhecimento com uma viagem lenta e maçante. Meu único contato com ela é através da janela do carro, uma pequena tela, em movimento. Acompanho uma longa sequência em que a cidade exibe sua aparente monotonia - uma calçada única, de um extremo ao outro. (VIDAL, p. 21)

Em outro momento, ao andar de ônibus pela cidade, a protagonista analisa seus acompanhantes dentro do veículo ao longo do deslocamento diário até a universidade, considerando que "enquanto passa pela janela a paisagem urbana, [vai] aos poucos aprendendo a reconhecer; [faz] parte desse microcosmo provisório como uma estátua viva" (VIDAL, p. 29). A referência à estátua viva nos faz crer que a personagem já foi, de fato, despida da corporalidade humana. Sente seu corpo como imitando o concreto - uma falsa resistência endurecida que deve sustentar sua permanência por ali até que seu objetivo seja alcançado, ou enquanto suportar. Sequer consegue buscar identificação com um dos vários grupos diaspóricos que habitam aquele lugar: poderia procurar estabelecer contatos com a comuni- 
dade latino-americana, ao longo dos quais seu espanhol e sua descendência argentina provavelmente abririam portas; ou com os brasileiros, compondo um grupo verde e amarelo onde poderia ser bem-vinda. No entanto, a protagonista não menciona em momento algum qualquer concepção de comunidade que considere viável para sua integração.

De acordo com Jennifer Bowering Delisle (2013, p.10), há, na maior parte das vezes, cinco características associadas à subjetividade diaspórica: 1. um deslocamento doloroso e a condição de perda; 2. uma contínua conexão com o país de origem; 3 . a formação de comunidades diaspóricas no exterior; 4 . a construção da pátria a partir de uma nova concepção do nacional, e não apenas em termos regionais; 5. uma sensação de diferença e marginalização no novo lar. Em Algum lugar, a protagonista não demonstra sensação de perda em relação ao que ficou para trás e tampouco o desejo genuíno de recriar algum senso de comunidade em seu novo local. Já no desencontro/encontro no aeroporto de Los Angeles somos informados que a protagonista não gostaria de "desaproveitar a possibilidade de um recomeço" (VIDAL, p.17). Portanto, crises entre o casal já estavam instaladas desde a viagem de partida. Nenhum dos dois sente ou expressa desejo de criar novos grupos comunitários, não se percebendo propriamente como migrantes ou imigrantes. Estão ali com propósitos de médio prazo - ela, cursar um doutorado, ele, acompanhá-la e continuar com seu trabalho de traduções. Todas as características que poderiam marcá-los como diaspóricos de fato não tomam lugar - a sensação de perda de algo não é explicitada, parecendo haver na maior parte do enredo comparações que não elevam ou destacam o lugar abandonado. Talvez apenas o quinto ponto destacado por Delisle se aplique, ou seja, há uma sensação de diferença e estranhamento em L.A. vivenciada pelo casal, mas isso também ocorre entre eles, na própria relação amorosa.

Contudo, ao reler mais tarde o guia sobre Los Angeles que comprara logo após a chegada, a protagonista reconhece algo que não percebeu de imediato:

Here is the deal: Los Angeles is not an easy place to grasp. It doesn't feel like any city you've ever known. It's vast and amorphous, with no clearly defined center. But the key to understanding-and appreciating-the place is to throw out the notion that it's a city at all. Estava na primeira página do guia. Como foi que não vi? (VIDAL, p. 24)

Percebe-se que a cidade é compreendida como um lugar sem histórias, sem promessas de possíveis vínculos, pelo menos pelo enfoque da voz narrativa. Assim, a única pessoa que acaba se tornando relativamente próxima da personagem principal em L.A. é uma coreana, com quem aquela divide um porão da universidade nas horas de estudo - uma espécie de ambiente de trabalho úmido, subvalorizado e infestado por pulgas onde as duas estudantes buscam sonhar com algum brilhantismo. Essa colega recomenda chamá-la de Lucy, já que seu nome original não seria pronunciável por parte de não asiáticos, todos os diálogos entre as duas se desenvolvendo em espanhol. $\mathrm{O}$ atalho via falsa nomeação, $\mathrm{o}$ uso do espanhol, língua que não é a nativa de nenhuma das duas mulheres e tampouco a língua oficial do local em que ora se inserem, a apresentação que se dá entre as duas através das pulgas que as picam de forma alternada, todos esses fatores, marcas da convivência possível, aproximam-nas e, ao mesmo tempo, dificultam o surgimento de uma amizade realmente mais profunda. Há distâncias e incompreensões entre elas que nunca podem ser vencidas. Quando a protagonista tenta indicar a Lucy em que ponto sua crise pessoal chegou, não apenas pelo iminente retorno de M. para o Brasil (que ela percebe como um abandono), mas pelo questionamento que passa a fazer de sua vida como um todo, a colega de ambiente de estudo se limita a afirmar que essa seria a melhor hora para aproveitar para avançar na tese, não percebendo a extensão do problema. É possível perceber que a cidade (que as uniu, de alguma forma) aproxima corpos, não vivências e trocas de fato.

Grosz (2011, p. 91) define 'corpo' em seu já referido texto como "uma organização concreta, material e animada de carne, órgãos, nervos, músculos e estrutura óssea à qual é conferida uma unidade, uma coesão e uma organização através de sua inscrição psíquica e social enquanto superfície e matéria-prima de uma totalidade integrada”. Aponta ainda que esse corpo é 
"organicamente/biologicamente/naturalmente incompleto" (idem). Ele só se prolongaria e existiria de fato através da ativação dentro do campo social, através das relações com seus outros. A protagonista de Vidal não vê essa possibilidade. Ela está sem grupo, sem elos, e não acredita que estes possam ser estabelecidos em seu novo local. Por não crer em qualquer prolongamento possível, sente-se limitada. O contexto de sua vida em L.A, que extrapola o apartamento silenciosamente dividido com M., não permite que laços outros sejam imaginados, fazendo com que seu corpo esteja como que solto no meio social, pouco importando as fronteiras geográficas, linguísticas e culturais que delimitam sua exclusão.

Em seu livro Diaspora, Memory and Identity: a search for home, Vijay Agnew (2008, p. 5) define consciência social no contexto diaspórico como algo "que se refere aos indivíduos que vivem em uma variedade de sociedades e culturas e que enfatizam seu senso de pertencimento ou exclusão, bem como seu senso de identidade". Nesse sentido, observamos que Vidal nos apresenta uma inconsciência ou insensibilidade social atrelada à protagonista, já que, tanto no período em que se encontra em Los Angeles, como mais tarde, no Rio, ela não consegue se perceber como parte das instituições pelas quais circula - universidade, família, casamento, tampouco construindo claros discursos que se oponham às mesmas. Reina uma indiferença aparentemente atrelada à exaustão, uma depressão, um sentimento de exclusão insolúvel.

Em determinada passagem do romance, através do monólogo interior, somos informadas quanto ao estado psicológico em que se encontra a protagonista: "Constato que se não tenho um espaço meu do lado de fora, meus pensamentos não me pertencem" (VIDAL, p. 21). Podemos nos perguntar se caberia pensar nesse corpo deslocado como um corpo realmente diaspórico, já que há uma absoluta falta de referências do social, do comunitário, nem mesmo como foco de contraposição, quer no Brasil, quer nos Estados Unidos. A comunidade foi implodida. Contudo, para nossa análise é produtivo que se leve em conta o que colocam Bliss S. Little e Benjamin J Broome (2010, p. 222), em sua definição de diáspora publicada na Encyclopedia of Identity:
Desde o final dos anos sessenta, a diáspora tem sido usada para designar grupos bastante diferentes de pessoas, incluindo-se aí as minorias étnicas e raciais. (...) Além de referir-se a grupos de pessoas, o termo diáspora tem também sido usado para referir-se à dispersão de uma língua ou cultura ou qualquer outro objeto que esteja afastado de sua origem ou centro.

O desenrolar da narrativa de Vidal nos faz crer que esse "objeto" em dispersão, afastado de sua origem, seria o corpo através do qual percebemos a voz narrativa em Algum lugar. É como se a situação fosse de absoluta suspensão - o corpo da protagonista está suspenso em L.A e também no Rio, pairando num espaço entre céu e terra, entre o mundo das ideias, que deveria organizar sua estadia, tornando-a profícua, mas onde o sucesso é mínimo, e o mundo das coisas, que não lhe diz nada. Lemos o que segue numa tentativa por parte da protagonista de comparar a vida cá e lá:

O Rio é uma sombra que de vez em quando
vejo passar, como uma nave sobrevoando a ci-
dade. Os pontos de comparação são poucos, só
a praia na verdade, que ainda assim é diferente
demais, mas me sinto tentada a sobrepor uma
geografia sobre a outra como para medir o grau
do meu deslocamento ou forçar uma adapta-
ção necessária. (VIDAL, p. 29)

Diversas autoras que trabalham com a escrita sobre (e na) diáspora têm feito referência à suspensão do corpo como um elemento a ser considerado. Pin-chia Feng (1999, p. 49), ao analisar o emblemático romance contemporâneo nipo-canadense Obasan, de Joy Kogawa, faz referências à existência da protagonista como que num "estado de suspensão". Brinda Mehta (2009, p. 118), em seu livro Identity, Diaspora, and Gender in Caribbean Women's Writing, aponta o que segue no que diz respeito à ideia de suspensão, ainda que se referindo ao contexto literário caribenho: "Esse corpo em suspensão é uma negação do processo de repetição, já que ele carrega em si a disjunção de sistemas culturais opostos e a violência das condições pós-modernas de vida imigrante, especialmente para as mulheres".

De acordo com tal ponto de vista, esse estado de suspensão, de perceber o corpo como um objeto erran- 
te e flutuante que fica explícito no romance Algum lugar, tem fortes ligações com o deslocamento vivenciado, quando uma revisão identitária se impôs à protagonista, sendo que a mesma nem quis estabelecer vínculos com comunidades do passado, na terra de origem, nem com novas, com as quais se defronta no espaço diaspórico. Talvez disso resulte que as cidades, ainda que dividindo e organizando a narrativa, não sirvam mais sequer como um entre lugar estável. Grosz (2011, p.92) entende por cidade "uma rede complexa e interactiva que relaciona, frequentemente de forma desintegrada e efectiva, um número de actividades sociais díspares, processos e relações imaginárias e reais, projectadas e efectivamente arquitectadas em termos geográficos, cívicos e públicos".

Em Algum lugar, as geografias das duas cidades centrais, tanto no curso de vida da protagonista quanto na própria arquitetura narrativa, na forma de capítulos que se alternam, não dialogam, qualquer tentativa de avaliação comparativa sendo imediatamente frustrada pela impossibilidade de justapor elementos tão diversos. É possível que essa subjacente incapacidade esteja atrelada mais à protagonista do que às cidades em si. Há uma passagem clara de busca de interação dessa para com as cidades representadas - no momento em que a personagem adquire uma planta para o apartamento quase sem vida e sem personalidade que divide com M. em Los Angeles, logo após perceber que o companheiro se mostra absolutamente fechado dentro do apartamento que dividem, vivendo um ciclo totalmente diferente do dela, inclusive no que se refere a horários e atividades. Lemos o papel que a nova planta deverá assumir, após ser carregada para casa:

Saí da loja entusiasmada com o meu gesto, mas sabendo que, vencido o vendedor, faltava enfrentar o ceticismo de M. Para isso também vinha me preparando, pois o gesto só faria sentido se conseguisse recuperar a casa de sua indiferença com algo de que é preciso cuidar, dia a dia, algo mais que um objeto, que poderá eventualmente denunciar um abandono. (VIDAL, p. 72)

O que talvez esteja também aí sendo apresentado como ainda outro pano de fundo, além dos países em questão e o papel secundário que esses assumem, é a solidão que, independente da companhia de M., se impõe. Um distanciamento de tudo e todos já se manifestava anteriormente e a busca pela planta de tamanho ideal, que ela pudesse carregar, apossando-se e responsabilizando-se por ela, indica que nossa protagonista também conta com um despertar de M., em verdadeiro estado de torpor, o apartamento tendo se tornado seu refúgio:

\begin{abstract}
Quando apagam as luzes e ele adormece, ela começa a ouvir seus próprios batimentos cardíacos e não consegue dormir. Um medo difuso, sem imagem, toma conta do seu pensamento. Seu corpo fica reduzido a um grão, um ponto ínfimo que poderá a qualquer instante desaparecer. Sente que se perde entre os lençóis, como um balão que em um segundo se esvazia, e tem que apalpar as pernas, os braços, a barriga para se certificar de que ainda existe. Mas a imagem mental de seu desaparecimento não se resolve nessa comprovação física; de olhos fechados, a sensação arremete de novo. Mais uma vez comprova a materialidade dos seus membros e mais uma vez tem certeza de que está desaparecendo. (VIDAL, p. 51)
\end{abstract}

Lemos aqui que o corpo material escapa, não dando garantias de vida concreta à voz que nos narra a estória. Enquanto a narradora toca seu próprio corpo para confirmar sua materialidade, tendemos a esfregar a capa do livro para ver se ele realmente existe ou se a estória já desapareceu.

\section{Pontos de interrogação: perguntas suspensas e sonhos inacabados}

Ao longo do romance de Vidal os(as) leitores(as) confrontam-se com perguntas soltas, um diálogo que a narradora estabelece consigo ou que gostaria de estabelecer com o companheiro, mas que nunca toma lugar de forma explícita. Daí estarem tais perguntas sempre dispostas antes ou depois dos sonhos que apresenta. Essas perguntas são em segunda pessoa, direcionadas a alguém, que nunca responde ou que sequer sabe que está sendo questionado: 


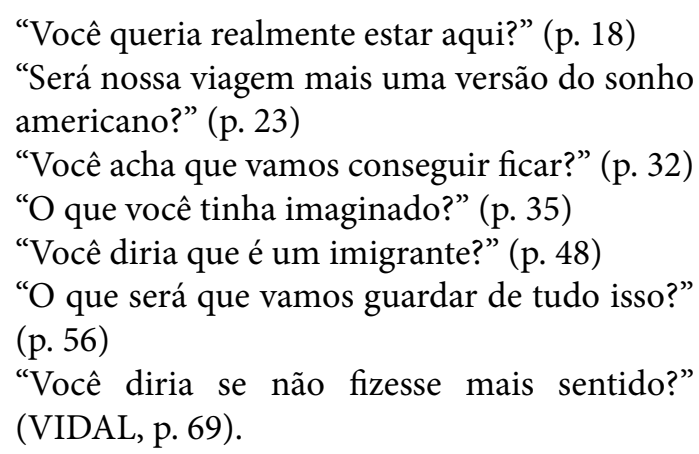

Mesmo essas perguntas soltas, perdidas e deslocadas em meio à narrativa, vão rareando, até que, depois do retorno ao Rio de Janeiro, voltam de forma ainda mais tênue:

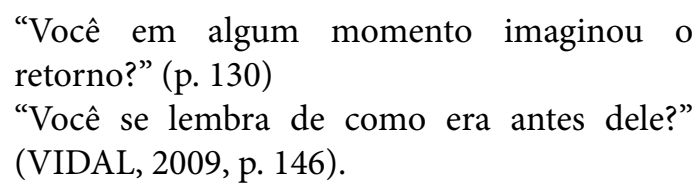

Perguntas dirigidas mentalmente a si mesma ou ao companheiro, mesmo que nunca verbalizadas, indicam aqui uma tentativa de entender a posição em que ambos se encontram. Como se o ato de reacessar o passado, refazer o caminho percorrido, pudesse fazê-los lembrar do porquê estão ali e, principalmente, para quê. Como aponta Halbwachs (2006, p. 29-30),

[s]e a nossa impressão pode se basear não apenas na nossa lembrança, mas também na de outros, nossa confiança na exatidão de nossa recordação será maior, como se uma mesma experiência fosse recomeçada não apenas pela mesma pessoa, mas por muitas. (...) Os fatos passados assumem importância maior e acreditamos revivê-los com maior intensidade, porque não estamos mais sós em representá-los para nós. Não os vemos agora como os víamos outrora, quando ao mesmo tempo olhávamos com os nossos olhos e com os olhos de um outro.

Até o nascimento de C., filho do casal, havia ao longo da narrativa de Vidal um constante e produtivo diálogo entre sonho e realidade. Conhecemos melhor a protagonista através dos sonhos que esta apresenta de forma desarticulada ao longo da narrativa, sem preocupação qualquer em interpretá-los e organizá-los cronologicamente. Vida e sonho se misturam de tal for- ma que propiciam o surgimento de dúvidas quanto ao que, de fato, acontece e o que se imagina. A voz enunciativa, nesses momentos, passa a falar consigo mesma em segunda pessoa, chamando-se de 'vocề, de forma semelhante ao que ocorre nas perguntas soltas, também em forma de diálogo/monólogo, que demarcam um território discursivo próprio ao longo da estória. Essa relação entre as perguntas, aparentemente soltas, e os sonhos, acaba soando como a construção de uma autoanálise, restando esse relato/diálogo consigo (ou para si) mesma, um resquício de comunicação: "Você sonha que acabou de chegar em Los Angeles. É meiodia e anda pelas ruas em volta do hotel, perto do que chamam de Financial District (...). Mesmo sendo horário de almoço, as calçadas estão praticamente desertas" (VIDAL, p. 23). Algumas páginas adiante, o ponto de referência sonhado é outro: "Você sonha que está no Rio. Está andando de noite por uma rua familiar. Reconhece o prédio, embora não tenha nada a ver com o verdadeiro. $O$ resto é totalmente estranho, mas você não se sente perturbada, pelo contrário (...). Você diz a M., que anda a seu lado: conheço tudo isso, mas não sei de onde" (VIDAL, p. 31).

Além de tentativas de localização geográficas bastante frequentes nos sonhos, que intercalam o Rio de Janeiro e Los Angeles como possíveis cenários, outro assunto frequentemente revisitado no estado onírico refere-se ao irmão. Seu nascimento, os primeiros anos de vida, a vivenciada chegada de um novo ser à casa da infância, a doença que o atacou, nunca mencionada claramente. A importância que o irmão teve/tem em sua vida não é tratada em estados de alerta, em diálogos reais, como se fosse por demais dolorosa para ser exposta à luz do dia e a uma gramática organizada. Mas os resquícios da memória afetiva estão lá e retornam nas horas caladas da noite, nos apresentando um lado mais emocional da personagem, que só emerge durante o sono. O mundo dos sonhos acaba estando relacionado a uma forma de rever o passado, acessar por outro ângulo experiências anteriores por demais dolorosas.

Há o registro de apenas um sonho que se volta ao motivo de estar ali - seu doutoramento, enfim, a tese que deve produzir: "Você sonha que terminou a tese. Está com o texto na mão, um bloco retangular bastante 
grosso, encadernado com uma capa azul, que carrega debaixo do braço por um longo corredor mal iluminado" (VIDAL, p. 60) . Ao seguir por esse corredor, encontra (no sonho) com a mãe, que lhe diz em espanhol: "Conseguiste terminar a tiempo! (...) Você lhe mostra o bloco azul e ela pergunta: sobre qué es? Sobre vos, você responde" (VIDAL, p. 60). No entanto, essa tese de doutorado, que tudo teria a ver com a mãe, é mais tarde abandonada. Quando as aulas de espanhol que tenta ministrar, bem como as que assiste como aluna de Pósgraduação, em resumo, quando a existência naquela cidade, de forma geral, começa a não mais fazer sentido, procura encontrar-se com Lucy, a conhecida coreana, na esperança de apostar em algum contato viável, mas ela também não mais frequenta o ambiente no porão que antes dividiam:

Constato que a presença dela me fazia avançar, mesmo sem saber para onde. Era como se ela fosse uma espécie de prova de que o que vim fazer ali não é um completo absurdo, já que existia outra pessoa naquele buraco pulguento, no subsolo do Rolfe Hall, que viera do outro lado do mundo para fazer algo parecido. (VIDAL, 2009, p. 83)

Portanto, ocorre, de fato, um entrelaçamento de insatisfações passíveis de serem lidas via sonhos, monólogos interiores, perguntas autorreferentes, tanto no que se refere à vida privada, à relação amorosa em crise, à ausência/morte do irmão, à ausência/presença provocadora da mãe, à tentativa de escrever uma tese que faça sentido para si e para a instituição. Há ainda um sonho sobre estar em um poço profundo, de onde "você"/ela consegue sair, mas que demarca a destruição de tudo que ficara do lado de fora. A partir disso, desistir e apagar o que foi vivido passa a tomar forma, com o intuito de não permitir que a narrativa e a voz narrativa se calem por completo.

O retorno ao Rio de Janeiro, depois que M. desistiu de permanecer em Los Angeles - “' 'Preciso ir embora' -, foi o que disse dez dias antes da partida" (VIDAL, p. 101), quando as coisas começaram a não fazer mais sentido, tornou impossível a finalização daquela etapa. Nessa época surge a referência a um sonho absoluta- mente curto: "Você sonha que está num quarto com um homem que não conhece. É só disso que se lembra” (VIDAL, p. 78). Também surge a certeza que a presença de M. era maior do que imaginara: "Vejo que M. era uma garantia de algo fora do sono; o corpo dele ao meu lado era um limite que desapareceu" (VIDAL, p. 107).

Assim como a volta à cidade do Rio de Janeiro, a desistência do doutorado, a decisão (ou não) por uma gravidez, todos esses são eventos não explicados pela protagonista, determinando mudanças radicais no rumo que o enredo seguia. Também há a sugestão de que escrever um livro seria importante, que representaria "uma viagem de um continente a outro. O livro falaria da invenção de um pertencimento; construiria uma genealogia, atravessando várias cidades, até voltar ao seu ponto de partida" (VIDAL, p. 112). Se a escritura do livro ocuparia o espaço que restou pelo abandono da tese nunca escrita, o filho também vem voluntária ou involuntariamente substituir antigos projetos: "O bebê por enquanto é apenas uma abstração, mas ocupa todo o espaço da minha vida: não existe mais presente, apenas um futuro sem forma que carrego numa barriga ainda lisa. Tenho muito medo de perdê-lo" (VIDAL, p. 130).

Após a primeira referência, em seus "diálogos solitários", através de mínimos sonhos que continuam a ocorrer após o nascimento do filho, nenhuma pergunta mais emerge, a voz que inquiria acabando por se calar. Os sonhos também diminuem: "Há semanas não me lembro de nenhum sonho"(VIDAL, p. 150). Presumese uma separação e, assim, essas perguntas jogadas a si mesma em segunda pessoa não fazem mais sentido. $\mathrm{O}$ corpo (e tudo que o compõe) sofre modificações:

\footnotetext{
Quando saí da maternidade, minha barriga era um saco semi vazio, como se alguma coisa tivesse ficado lá dentro e precisasse ainda ser expelida. Demorei para entender que aquele agora era o meu corpo. Comprei uma cinta bem apertada e o submeti a ela dia e noite. Um mês depois o saco continuava lá, um pouco menor (VIDAL, p. 142).
}

Não apenas a protagonista passa a perceber que seu corpo é outro, como esse outro corpo é agora diretamente vinculado ao filho. "Quando ele abre a boca so- 
bre mim, não há sombra de dúvida: eu sou ele: ele não diferencia seu corpo do meu. Estou esperando a creche para, justamente, lhe fazer entender que não, estabelecer fronteiras entre nós" (VIDAL, p. 145). M. participa dos primeiros anos da vida de C. (também não completamente nomeado), mas as perguntas não estão mais lá, talvez por não lembrarem mais de como tudo era antes, antes da viagem, antes do filho. A separação do casal ocorre sem brigas, tão silenciosa quanto se tornara a vida entre os dois e a narrativa sobre eles.

Ao avistar M. de longe beijando uma moça, que em seguida entrou num táxi, ela sentiu o corpo gelar. Começou a tremer de frio, como se a temperatura tivesse caído subitamente. (...) Se o barulho dos carros e dos ônibus teria tornado qualquer conversa impossível naquele lugar, não falaram nada porque nenhum dos dois sabia o que dizer. (...) Cumpriram a rotina nesse dia e durante o que restava da semana. No sábado, ele juntou algumas roupas numa mala e se mudou para a casa da sua mãe. (VIDAL, p. 160)

Ao perceber que o filho, ainda criança, tem crises de pertencimento, esteja onde estiver, a protagonista parece aceitar seu estado deslocado, suspenso, sua falta de integração, como vemos no diálogo:

'Mãe, eu quero ir para algum lugar'.

'A gente está indo para casa'.

'Não, mãe quero ir para outro lugar'.

'A casa do seu pai'? pergunto.

'Não, outro lugar', ele repete.

'Que lugar'?

'Algum lugar' (VIDAL, p. 159).

Algum lugar fala de uma busca intensa por uma outra forma de vida, por novos espaços e configurações para o privado. É interessante considerar aqui o que defende Sissy Helff ao discutir o romance contemporâneo, percebendo o entre lugar como ampliado, transcultural:

Eu defino um romance como transcultural se um dos seguintes aspectos se aplicar: primeiro, se o narrador e/ou a narrativa desafiar a identidade coletiva de uma determinada comunidade; em segundo lugar, se as experiências de cruzar fronteiras e identidades transnacionais caracterizarem os modos de vida (Lebenswelt) dos narradores; e em terceiro, se as noções tradicionais de lar forem contestadas. (HELFF, 2008, p. 83)

C., o filho do casal, fala dessa busca por algo que não é propriamente o lar, pelo menos não a antiga noção desse como local acolhedor, seguro. Ele quer ir para algum lugar indefinível, que continua a alimentar o desejo, ainda que o simples desejo de busca. Certamente filho e mãe tampouco estão em busca por uma comunidade estável, principalmente a mãe, que duvida dessa possibilidade tanto em sua terra natal quanto nos novos territórios pelos quais continua a se mover e nos quais permanece em suspensão.

Após esse diálogo entre C. e sua mãe, de forma enganosa, somos levadas a crer que a última parte da narrativa se passará em Los Angeles, título da derradeira seção de Algum lugar, como insinuando o fechamento de um ciclo. Mas não, surpreendentemente, a narrativa se desenvolve em Buenos Aires, a convite da mãe/avó argentina. É como se a própria narradora tivesse sido pega de surpresa - não retornaria a Los Angeles, mas a outra cidade que também havia feito parte de sua vida, principalmente nas férias da infância, deixando todos os ciclos em aberto, sem fechamento possível. Contudo, ali, na terra de sua mãe, onde "por acaso" também nasceu, a voz narrativa consegue fazer paralelos, estabelecer semelhanças entre cidades, ruas, locais argentinos e cariocas. Los Angeles acaba sendo o nome do antigo cinema portenho onde mãe e filho aproveitam uma atividade não turística, algo "normal", como C. solicitara. Assistem ao filme "O Patinho Feio", sendo que, na saída do cinema Los Angeles, o filho da protagonista embarca num carrossel antigo disposto em frente à sala de projeção. Acomodado "num cavalo vermelho e branco, de onde ele acenará [para mim] como se estivesse partindo para uma longa viagem" (VIDAL, 2009, p. 170), C. é a personagem que encerra a narrativa, abrindo um novo ciclo - o movimento deixa de pendular, quase bipolar entre Rio e Los Angeles, para entrar, via novos loopings, em outras esferas e estratosferas. Algum lugar sempre haverá para ser ocupado através da imaginação e, por vezes, a suspensão pode até tornar-se lúdica. 


\section{Considerações finais}

Concordando com Mehta na introdução a seu já mencionado livro (2009, p. 1), onde a autora propõe que "a diáspora não é um conceito homogêneo e tampouco uma experiência unidimensional", deveríamos pensar em Algum lugar como uma estória em que diferentes diásporas coabitam lugares, em experiências transculturais justapostas, mas onde nem sempre o contato ou a troca, apesar da proximidade em relação ao(s) outro(s), torna-se possível, seja por motivos derivados da condição psicológica dos envolvidos, seja por traumas anteriores não apenas no plano individual, mas coletivo. Há fraturas expostas criadas por uma voz narrativa que não obtém imediato sucesso nas negociações que tenta estabelecer entre os parâmetros culturais, geográficos, que demarcam seu estado diaspórico em qualquer lugar em que esteja, uma diáspora onde a comunidade desapareceu, a cultura foi perdendo o viço, onde o 'trans' impera. Segundo Janice K. Keefer (1995), a escrita transcultural se engaja em ultrapassar as marcas redutoras das expressões 'imigrante' e 'étnica', já que essa produção não seria escrita (e lida) exclusivamente para ou por membros de uma dada comunidade. Ou seja, se Algum lugar nos apresenta uma protagonista que não se sente em casa em seu país e tampouco se sente imigrante no local para o qual se desloca, compondo uma história que não fala de uma raiz, de um lugar único de identificação, o que temos aí é sim uma literatura que também paira entre culturas, entre nações, entre cidades, entre abreviações (C. e M.). Não podemos definir previamente o qualificador do 'lugar' a partir do qual a narrativa é escrita - algum, nenhum, um, outro, já que a voz narrativa insiste na pura e explícita suspensão. Como leitores e leitoras, resta-nos acompanhar os movimentos multi dimensionais que nos são apresentados por Vidal via seu corpo textual, aceitando os malabarismos deste como parte do desejo de permanecer suspensa entre cidades, culturas, línguas e literaturas.

\section{Notas}

1. Todas as traduções do inglês e espanhol são de responsabilidade da autora do artigo.

2. Todas referências ao romance de Vidal serão doravante citadas apenas pelo número de página, sendo a respectiva edição relacionada nas referências bibliográficas.

\section{Referências}

AGNEW, Vijay (ed.) Diaspora, memory and identity: a search for home. Toronto: University of Toronto Press, 2008.

ALMEIDA, Sandra Regina Goulart. Corpo e escrita: imaginários literários. In: Revista UFMG, Belo Horizonte, v. 19, n01/02, p. 92-100, jan/dez 2013.

"Mobilidades culturais, geográficas afetivas: espaço urbano e gênero na literatura contemporânea". In: DALCASTAGNE, Regina e LEAL, Virginia Maria Vasconcelos (Org.). Espaço e gênero na literatura brasileira contemporânea. Porto Alegre: Ed Zouk, 2015 , p. 15 - 39.

ANZALDÚA, Glória. Borderlands/ La Frontera: The New Mestiza. San Francisco: Aunt Luke Books, 1987.

ANZALDUA, Glória e MORAGA, Cherrie. This bridge called my back: writings by radical women of color. New York: Kitchen Table Press, 1983.

BORDO, Susan R. O corpo e a reprodução da feminidade: uma apropriação feminista de Foucault. In: JAGGAR, Alison M., BORDO, Susan R. (Orgs.). Gênero, corpo, conhecimento. Tradução de Britta Lemos de Freitas. Rio de Janeiro: Record: Rosa dos tempos, 1997. p. 19-41.

. Feminism, western culture and the body. Berkeley: University of California Press, 1993, p. 225-248.

BRAH, Avtar. Cartographies of diaspora: contesting identities. London: Routledge, 1996.

CAMPS, Assumpta. A mitad de camino entre aquíy allá, em medio de quién sabe dónde: traducirla/desde la frontera. in: Red de Revistas Científicas de América Latina, el Caribe, Espana Y Portugal, Universitat de Valência, Espana, n.3, 2011. p. 337-357.

DELISLE, Jennifer Bowering. The newfoundland diaspora: mapping the literature of out-migration. Ontario. Canada: Wilfried Laurier University Press, 2013.

FENG, Pin-chia. The female Bildungsroman by Toni Morrison and Maxine Hong Kingston: a postmodern reading. New York: Peter Lang, 1999.

GROSZ, Elizabeth. "Corpos-cidades". In: MACEDO, Ana Gabriela e RAYNER, Francisca. Gênero, cultura 
visual e performance: antologia crítica. Porto: Húmus/ Universidade do Minho, 2011, p. 89-100.

HALBWACHS, Maurice. A memória coletiva. Trad. Beatriz Sidou. 2.ed. São Paulo: Centauro, 2006.

HELFF, Sissy. Shifting perspectives: the transcultural novel. In: Transcultural english studies: theories, fictions, Realities. Frank Schulze-Engler and Sissy Helff (eds.). Amsterdam/New York: Rodopi, 2008, p. 75-97.

KEEFER, Janice K. From Mosaic to Kaleidoscope: Out of the Multicultural Past Comes a Vision of a Transcultural Future. In: Books in Canada, vol 20, n 6, 1991, p. 13-16.

KLAHN, Norma. Literary mappings: autobiographical (dis)placements by Chicana writers. In: HURTADO, Aída et al (Orgs.). Chicana feminism: a critical reader. London: Duke University Press, 2003, p. 58-76.

LITTLE, Bliss; BROOME, Benjamin. Diaspora. In: JACKSON, Ronald; HOGG, Michael (eds.). Encyclopedia of identity. Thousand Oaks, CA: SAGE Publications, 2010, p. 101-110.

MEHTA, Brinda. Identity, Diaspora, and Gender in Caribbean Women's Writing, New York: Palgrave/ MacMillan, 2009.

RICH, Adrienne. Notas para uma política de localização. In: Macedo, Ana Gabriela (Org.). Gênero, identidade e desejo: antologia crítica do feminismo contemporâneo. Trad. Maria José Gomes Lisboa: Cotovia, 2002, p. 15-35.

SANDOWSKI-SMITH, Claudia. Border fictions globalization, empire and writing at the boundaries of the United States. Charlottesville and London: University of Virginia Press, 2008.

SMURMUK, Mônica; IRWIN, Robert Mekee. Dicionário de Estudios culturales Latinoamericanos. Mexico: Ed. Instituto Mora, 2009.

VIDAL, Paloma. Algum lugar. Rio de Janeiro: 7 Letras, 2009. 